\title{
ИПОТЕЧНОЕ КРЕДИТОВАНИЕ КОММЕРЧЕСКОЙ НЕДВИЖИМОСТИ БАНКАМИ КАК ФАКТОР РАЗВИТИЯ МАЛОГО БИЗНЕСА В РОССИИ
}

\author{
(c) 2019 Савинова Валентина Андреевна \\ доктор экономических наук \\ Самарский государственный экономический университет, Россия, Самара \\ E-mail:SavinovaVA@yandex.ru \\ (c) 2019 Борлакова Татьяна Евгеньевна \\ преподаватель кафедры Финансы и кредит \\ Самарский государственный экономический университет, Россия, Самара \\ E-mail: borlakova@bk.ru
}

Рассматриваются теоретические основы ипотеки недвижимого имущества, состояние развития российского рынка коммерческой недвижимости, выявляются проблемы его функционирования и зарубежный опыт развития ипотеки нежилых помещений.

Ключевые слова: ипотека, ипотечное кредитование, коммерческая недвижимость, субъекты малого и среднего бизнеса, предпринимательство, единые стандарты кредитования.

Развитие социально-экономических видов деятельности в России направлено на успешное выполнение одной из главных задач государства - повышение валового внутреннего продукта (ВВП). Решению данной задачи во многом будет способствовать «Стратегия повышения финансовой доступности на период 2018-2020 г.г.» Реализация положений рассматриваемого документа направлена на широкое использование новых информационных технологий субъектами малого и среднего предпринимательства, в том числе жителями отдаленных и труднодоступных территорий.

В решении этих вопросов важная роль отводится Банку России. В частности, разработка и внедрение единых стандартов кредитования Банком России позволит снизить риски кредитных организаций, повысить финансовую устойчивость кредитного сектора и снизить уровень процентных ставок по кредитам. Необходимость реализации этой задачи охватывает все сферы экономики страны и диктуется рядом факторов.

Так, доля российского ипотечного кредитования в ВВП более чем в 3 раза меньше аналогичных показателей в странах центральной и восточной Европы. Например: в Чехии данный показатель находится на отметке $16,6 \%$, в Польше $-20 \%$, во Франции и США $-55 \%$ и $50 \%$ соответственно, в Норвегии - 100\%.

Рост ВВП должен обеспечиваться не только за счет добывающих отраслей, как наиболее развитых, но и других отраслей реального сектора экономики. Значительная роль в этих процессах отводится предприятиям малого и среднего бизнеса. Вместе с тем необходимо отметить, что объем российского ипотечного нежилого кредитования даже в периоды высоких темпов развития экономики остается существенно ниже чем в других странах с развитыми экономиками.

Коммерческая ипотека, так называемая бизнес-ипотека, сегодня является выгодным инструментом поддержки малого и среднего бизнеса. Ее содержание заключается в том, что покупка коммерческой недвижимости осуществляется под ее же залог. Можно отметить, что теоретические основы сущности ипотеки не имеют значительных различий, ибо жилая недвижимость приобретается населением также под ее залог. Различие заключается в использовании приобретенной недвижимости. Приобретая недвижимость в ипотеку, предприниматели размещают на ее территории офисы, склады, места оказания услуг в целях получения прибыли от сдачи указанных объектов в аренду.

Таким образом, ипотечный кредит нежилой направленности можно определить как ссуду, предоставляемую кредитными организациями для покупки нежилых помещений с целью использования их в коммерческой деятельности, залогом по которому выступает приобретаемый объект.

Основная задача государства в развитии ипотечного кредитования заключается в создании законодательной базы и ее нормативном 
регулировании в целях снижения финансовых рисков и повышения доступности получения каждого вида кредита для российских граждан.

Правовая база регулирования ипотечного кредитования в Российской Федерации представлена в первую очередь Федеральным законом № 102-Ф3 «Об ипотеке (залоге недвижимости)» от 16 июля 1998 г. (с изм. и доп.), а также рядом статей Конституции Российской Федерации, Гражданского Кодекса, Жилищного Кодекса. При этом положения Закона об ипотеки имеют первостепенное значение.

$\mathrm{K}$ участникам ипотечного кредитования предъявляются следующие требования: статус резидента Российской Федерации; наличие государственной доли в уставном капитале не более чем 25\%; отсутствие просроченной задолженности перед государственными органами и контрагентами. Кроме того, юридическое лицо не должно быть вовлечено в процедуру банкротства.

Что касается физических лиц, здесь также имеются определенные ограничения: обязательно наличие гражданства (только граждане Российской Федерации) и достижение возраста 21 года. Возможность принимать участие в ипотечных программах ограничено возрастом в 65 лет.

Данный вид кредитования ориентирован в большинстве своем на юридических лиц, в качестве которых выступают коммерческие организации и учреждения. Не являются исключением и индивидуальные предприниматели.

Рынок недвижимости всегда привлекал предпринимателей, желающих выгодно вложить капитал с целью получения прибавочной стоимости. Такая тенденция сформировалась исторически, ибо вложения в коммерческую недвижимость позволяет сохранить собственный капитал от достаточно частых происходящих в экономике инфляционных процессов. В первую очередь это касается рынка коммерческой недвижимости, на котором обращаются здания и сооружения, помещения для организации производственной деятельности, касающейся, в том числе и торговли, общественного питания и других видов деятельности. Одним из наиболее привлекательных сегментов рынка коммерческой недвижимости остается рынок торговых помещений.

Следует отметить, что рынок офисных помещений также отличается достаточно высо- ким уровнем развития и объясняется тем, что банковские структуры зачастую приобретают недвижимость в целях развития новых направлений бизнеса или уже действующих.

Еще одним сегментом коммерческой недвижимости могут выступать производственные помещения, используемые в качестве технопарков, промышленных зон и др.

Вместе с тем ипотечное кредитование является необходимым в развитии экономики большинства стран и в первую очередь в жилищном строительстве. Выступая основным механизмом решения жилищных проблем населения, а также инструментом стимулирования спроса на рынке недвижимости и строительства, ипотечное кредитование обеспечивает существенный приток финансовых ресурсов в производственную сферу. Таким образом, можно утверждать, что ипотечное кредитование недвижимости выступает одной из предпосылок экономического роста в стране. Вместе с тем, в отличие от жилищного кредита, кредит под коммерческую недвижимость следует квалифицировать как движение капитала. В процессе использования приобретаемой недвижимости формируется источник возврата кредита. С этих позиций он является менее рискованным [1].

В соответствии с другой точкой зрения «ипотечное кредитование - «это предоставление банками долгосрочных кредитов на приобретение или строительство недвижимости под залог недвижимого имущества» [2].

Интересной представляется позиция, рассматривающая ипотечное кредитование как «формирование условий для устойчивого роста российской экономики путем вложения средств в строительство, развития смежных с ним отраслей, а также создания новых рабочих мест и вовлечения в оборот неликвидных сбережений» [3].

Несмотря на то, что кредитование нежилых помещений является более привлекательным по сравнению с жилой недвижимостью, а также характеризуется более короткими сроками кредитования и достаточно высокими процентными ставками, оно не получило достаточного развития в банковской сфере. Так, по оценкам экспертов, кредитование коммерческой недвижимости под ипотеку осуществляется в России не более чем 10-ю процентами банков, при этом доля ипотечных кредитов на покупку коммерческой недвижимости составляет около одного процента от общего числа ипотечных кредитов. 
Как показывает практика развития ипотечного нежилого кредитования, максимальный срок погашения задолженности по ипотеке находится в интервале 5-10 лет. Можно отметить, что рассматриваемый интервал характерен и для погашения задолженности по ипотечному жилищному кредиту. Практика ипотечного жилищного кредитования показывает, что население Российской Федерации погашает ипотечный кредит в среднем за 5-7 лет. Срок размещения ипотечных облигаций составляет также 5-7 лет. Таким образом, можно констатировать тесную взаимосвязь основных элементов ипотечного кредитования.

На сегодня в развитии ипотечного кредитования нежилой недвижимости выделяются следующие проблемы:

1) у банков отсутствуют долгосрочные финансовые ресурсы, которые можно было разместить на более длительные сроки по сравнению с жилой недвижимостью. В данном случае необходимо отметить, что данная проблема затрагивает не только нежилую недвижимость, но и ипотечное кредитование жилья в первую очередь.

2) риски кредитования субъектов малого и среднего предпринимательства выше, чем в корпоративном секторе, ввиду недостаточно прозрачного бизнеса заемщиков, меньшего объема запасов и резервов, пониженной платежной дисциплины.

3) повышенные кредитные риски влекут за собой более высокие ставки и сокращенные сроки кредитования заемщиков по сравнению с корпоративными заемщиками.

4) для малых предприятий на старте возникают две проблемы: наличие свободных финансовых ресурсов и помещения для ведения бизнеса.

Однако главной причиной низкого уровня развития малого и среднего бизнеса стало иное отношение к системе кредитования. Несмотря на то, что достаточно активно развивается реклама и заверения в развитии бизнес-проектов, предприниматели стали более тщательно подходить к его масштабному росту. В значительной доле это объясняется отсутствием достаточного финансирования, финансовых поручителей, а зачастую - и квалифицированного бизнес-плана.

Малый бизнес остро нуждается в кредитах для своего развития, но по оценкам, только 16\% предпринимателей получают займы от банков. Главной причиной низкой закредитованности малого бизнеса является его незначительная прибыль и высокие риски, связанные с их деятельностью. Второй существенной причиной выступает отсутствие залога, не позволяющего банкам кредитовать свой бизнес. Кроме того, у представителей малого бизнеса, как правило, отсутствуют финансовый анализ и отчетность деятельности, не позволяющие в силу высоких кредитных рисков осуществлять кредитные операции банками с такого рода заемщиками.

Также серьезной проблемой для малого бизнеса является внесение первоначального взноса как гарантии для банка их возврата.

Рассмотрим возможности кредитования малого и среднего бизнеса в России (см. табл. 1). Как видно из представленных данных, объемы кредитования субъектов малого и среднего предпринимательства имеют незначительные размеры. Вместе с тем для развития бизнеса малым предприятиям требуются производственные, офисно-торговые и складские помещения. Однако многие из них предпринимателей не могут приобрести коммерческую недвижимость без кредитных средств.

Отметим, что этой проблеме столько лет, сколько существует частный бизнес в России. Но если раньше предприятия могли позволить себе снимать помещение на протяжении нескольких лет, то произошедшие в последние годы на рынке недвижимости скачки цен вызвали резкий подъем арендных ставок и повышение рисков предпринимателей к бизнесу.

В качестве одного из направлений снижения рисков малого бизнеса можно рассматривать

Таблица 1. Характеристика кредитования малого и среднего бизнеса в России

\begin{tabular}{|c|c|c|c|}
\hline \multirow{2}{*}{ Период } & \multicolumn{3}{|c|}{ Объемы кредитования субъектов, млн. руб. } \\
\cline { 2 - 4 } & Всего & Субъекта МСБ & Доля субъекта МСБ,\% \\
\hline 01.01 .2017 & 15015771 & 5162 & 0,03 \\
\hline 01.01 .2018 & 42928749 & 5984 & 0,01 \\
\hline 01.01 .2019 & 48436678 & 6626 & 0,01 \\
\hline
\end{tabular}

Источник: Банк России. Статистический бюллетень Банка России № 3. Москва 2019 
Таблица 2. Доля и динамика просроченной задолженности по предоставленным кредитам нефинансовым организациям

\begin{tabular}{|c|c|c|c|c|}
\hline \multirow{2}{*}{ Период } & \multirow{2}{*}{\begin{tabular}{c} 
Объем предостав- \\
\cline { 3 - 5 }
\end{tabular}} & \multicolumn{3}{|c|}{ Задолженность по представленным кредитам } \\
\cline { 3 - 5 } & млн. руб. & Всего & $\begin{array}{c}\text { Просроченная } \\
\text { задолженность }\end{array}$ & $\begin{array}{c}\text { Доля просроченной } \\
\text { задолженности,\% }\end{array}$ \\
\hline 01.01 .2017 & 5162 & 4150 & 619 & 14,9 \\
\hline 01.01 .2018 & 5984 & 4013 & 601 & 15,0 \\
\hline 01.01 .2019 & 6626 & 4042 & 500 & 12,4 \\
\hline
\end{tabular}

Источник: Банк России. Статистический бюллетень Банка России № 3. Москва 2019

создание «бизнес - инкубаторов». Отметим, что они важны не только малым предприятиям, но и региону в целом.

Как и все кредитные операции, в том числе и операции с коммерческой недвижимостью сопряжены с кредитными рисками. На их формирование оказывают влияние различные факторы и в первую очередь отсутствие статистики коммерческой недвижимости. Как результат, ставки за пользование ипотечным нежилым кредитом значительно выше ставок ипотечного жилищного кредитования. Они варьируют в интервале 12-14\% при обязательном первоначальном взносе в размере $25-40 \%$.

В рассматриваемом периоде доля просроченной задолженности предприятий малого бизнеса получила тенденцию снижения и находится в интервале 15-12\% (см. табл. 2).

По данным таблицы видно, что доля просроченной задолженности средних и малых предприятий в общем объеме кредитной задолженности перед банками получила тенденцию снижения.

В настоящее время крупные банки активно наращивают кредитование субъектов малого и среднего предпринимательства, в том числе при поддержке государственных фондов.

Изучение опыта зарубежных стран в области ипотечного кредитования показывает, что в его сферу активно вовлекаются объекты нежилой (коммерческой) недвижимости. В частности в этих целях в Германии функционируют специализированные банки или банки со специальными заданиями, выполняющие важные народнохозяйственные функции по стимулированию определенных сфер экономики. Так, «ИКБ Дойче Индустрибанк АГ» - это банк промышленных товаров, занимающийся выдачей долгосрочных кредитов предприятиям, в частности выдачи кредитов на покупку нежилой недвижимости.

В США распространена система предоставления земельными банками ипотечных кредитов фермерам на льготных условиях. Банки управляются Фермерской кредитной организацией.

Решение поставленных вопросов позволит сформировать условия для развития ипотечного кредитования коммерческой недвижимости, спрос на которую у хозяйствующих субъектов, включая малый бизнес, постоянно растет.

\section{Библиографический список}

1. Савинова. В.А., П.Д. Семиков. Ипотечное кредитование коммерческой недвижимости как фактор развития малого предпринимательства и экономического роста в России. Самарский государственный экономический университет. 2007.

2. Лепехин И.А. Правовая природа кредитования, обеспеченного ипотекой. Москва. 2012.

3. Карташов К.А. Проблемы и перспективы ипотечного рынка в России(опыт развития ипотечного кредитования на примере Великобритании). Вопросы экономики и права. 2011. № 3. 